Article

\title{
Citrus junos Tanaka Peel Extract and Its Bioactive Naringin Reduce Fine Dust-Induced Respiratory Injury Markers in BALB/c Male Mice
}

\author{
Dong-Hun Lee ${ }^{1}$, Jin-Kyung Woo ${ }^{1}$, Wan Heo ${ }^{2}$, Wen-Yan Huang ${ }^{1}$, Yunsik Kim ${ }^{3}$, Soohak Chung ${ }^{3}$, \\ Gyeong-Hweon Lee ${ }^{3}$, Jae-Woong Park ${ }^{3}$, Bok-Kyung Han ${ }^{1}$, Eui-Chul Shin ${ }^{4}$, Jeong-Hoon Pan ${ }^{5}$ (D), Jae-Kyeom Kim ${ }^{5}$ \\ and Young-Jun Kim ${ }^{1, *}$
}

1 Department of Food and Biotechnology, Korea University, Sejong 30019, Korea; dhanmin@korea.ac.kr (D.-H.L.); wlsrud5877@korea.ac.kr (J.-K.W.); flyhighwy@korea.ac.kr (W.-Y.H.); hanmoo@korea.ac.kr (B.-K.H.)

2 Department of Food Science and Engineering, Seowon University, Cheongju 28647, Korea; 01062033526@seowon.ac.kr

3 Lotte R\&D Center, Seoul 07594, Korea; yunsik.kim73@lotte.net (Y.K.); soohak.chung@lotte.net (S.C.); ghlee@lotte.net (G.-H.L.); jaewoong_park@lotte.net (J.-W.P.)

4 Department of Food Science, Gyeongsang National University, Jinju 52828, Korea; eshin@gnu.ac.kr

5 Department of Behavioral Health and Nutrition, University of Delaware, Newark, DE 19716, USA; jhpan@udel.edu (J.-H.P.); jkkim@udel.edu (J.-K.K.)

* Correspondence: yk46@korea.ac.kr; Tel.: +82-44-860-1040

\section{check for} updates

Citation: Lee, D.-H.; Woo, J.-K.; Heo, W.; Huang, W.-Y.; Kim, Y.; Chung, S.; Lee, G.-H.; Park, J.-W.; Han, B.-K.; Shin, E.-C.; et al. Citrus junos Tanaka Peel Extract and Its Bioactive Naringin Reduce Fine Dust-Induced Respiratory Injury Markers in BALB/c Male Mice. Nutrients 2022, 14, 1101. https://doi.org/10.3390/ nu14051101

Academic Editor: Winston Craig

Received: 14 February 2022

Accepted: 3 March 2022

Published: 5 March 2022

Publisher's Note: MDPI stays neutral with regard to jurisdictional claims in published maps and institutional affiliations.

Copyright: (C) 2022 by the authors. Licensee MDPI, Basel, Switzerland. This article is an open access article distributed under the terms and conditions of the Creative Commons Attribution (CC BY) license (https:// creativecommons.org/licenses/by/ $4.0 /)$.

\begin{abstract}
Particulate matter (PM) 10 refers to fine dust with a diameter of less than $10 \mu \mathrm{m}$ and induces apoptosis and inflammatory responses through oxidative stress. Citrus junos Tanaka is a citrus fruit and contains bioactive flavonoids including naringin. In the present study, we aimed to identify the preventive effect of Citrus junos Tanaka peel extract (CPE) against $\mathrm{PM}_{10}$-induced lung injury. As a proof of concept, NCI-H460 cells were treated with CPE $(800 \mu \mathrm{g} / \mathrm{mL}, 12 \mathrm{~h})$ in conjunction with $\mathrm{PM}_{10}$ to examine intracellular antioxidative capacity in the pulmonary system. In an in vivo model, male BALB/c mice ( $n=8$ /group) were randomly assigned into five groups: NEG (salinetreated), POS (PM 10 only), NAR (PM $10+$ naringin, $100 \mathrm{mg} / \mathrm{kg}), \mathrm{CPL}\left(\mathrm{PM}_{10}+\mathrm{CPE}\right.$ low, $\left.100 \mathrm{mg} / \mathrm{kg}\right)$, and $\mathrm{CPH}\left(\mathrm{PM}_{10}+\mathrm{CPE}\right.$ high, $\left.400 \mathrm{mg} / \mathrm{kg}\right)$. Intervention groups received dietary supplementations for 7 days followed by $\mathrm{PM}_{10}$ exposure (100 mg/kg, intranasal instillation). Compared to the NEG, the CPE decreased to $22 \%$ of the ROS generation and significantly increased cell viability in vitro. The histological assessments confirmed that pulmonary damages were alleviated in the $\mathrm{PM}_{10}+\mathrm{CPL}$ group compared to the POS. Pro-inflammatory cytokines and NF- $\mathrm{kB}$ /apoptosis signaling-related markers were decreased in the $\mathrm{PM}_{10}+\mathrm{CPL}$ group compared to the POS. These results indicated that $\mathrm{CPE}$ showed promising efficacy in preventing pulmonary injuries in vivo. Such protection can be explained by the anti-oxidative capacity of $\mathrm{CPE}$, likely due to its bioactives, including naringin (7.74 mg/g CPE). Follow-up human intervention, as well as population-level studies, will further shed light on the preventive efficacy of CPE against pulmonary damage in humans.
\end{abstract}

Keywords: Citrus junos Tanaka; naringin; fine dust; particulate matter 10; pulmonary; apoptosis

\section{Introduction}

Particulate matter $10\left(\mathrm{PM}_{10}\right)$ refers to fine dust with a diameter less than $10 \mu \mathrm{m}$, and it is known that the smaller the particle size, the more fatal [1]. Exposure to $\mathrm{PM}_{10}$ can cause bronchial and cardiovascular diseases. Since it is mainly absorbed through respiration, many studies related to pulmonary inflammation were reported, while reactive oxygen species (ROS)/apoptosis/NF- $\kappa \mathrm{B}$ are spotted as major mechanisms to explain its toxicity [2]. Thus, it is a reasonable premise to identify a safe dietary antioxidant(s) to mitigate $\mathrm{PM}_{10}$-induced pulmonary damages. Relatedly, studies demonstrated that natural 
product extracts (e.g., tart cherry and pomegranate) reduce inflammatory response induced by $\mathrm{PM}_{10}$ in various study models [3-5]. For instance, Lee et al. reported that medicinal herb extract ameliorates $\mathrm{PM}_{10}$-induced inflammatory responses; responsible active compounds therein were antioxidants (e.g., baicalin and schizandrin) [6]. Hitherto, few human studies are available if chronic dietary antioxidants (and/or a mixture of extracts) are negatively associated with $\mathrm{PM}_{10}$-related diseases.

Citrus junos Tanaka (also known as Yuja or yuzu) is a citrus fruit of the family Rutaceae and is mainly consumed as tea and sauce [7]. It has been long used as a traditional medicine in Northeast Asian countries to treat bronchial and respiratory systems [8]. In particular, in its peel, there are various bioactives including naringin and hesperidin; naringin is a well-known active compound that can attenuate inflammation, cytotoxicity, and oxidative stress [9]. Preventive potential yuzu was reported in various disease models; one example is a preclinical study where Citrus junos Tanaka prevented dextran sodium sulfate-induced colitis via inhibiting the activation of endogenous NF- $\mathrm{BB}$ signaling pathway by suppressing the translocation of p65 [10]. In another study, Citrus junos Tanaka and its bioactive (i.e., naringin) ameliorated pulmonary damages in acrolein inhaled mice models [11,12]. Citrus junos Tanaka decreased ROS accumulation and p53-dependent apoptotic signaling and naringin suppressed phosphorylation of p65 via quenching acrolein-induced ROS. Studies utilized acrolein-induced pulmonary provide mechanistic insights related to yuzu and naringin, yet an evitable limitation is that humans are exposed to a mixture of inhalation toxicants (e.g., $\mathrm{PM}_{10}$ ), thus making it less translational.

Despite the wide scope of physiological effects of Citrus junos Tanaka and its bioactive compound (naringin), no research has examined their roles in $\mathrm{PM}_{10}$-induced respiratory toxicity. To this end, our study aimed to test our hypothesis that water extract of Citrus junos Tanaka and naringin will prevent $\mathrm{PM}_{10}$-induced pulmonary inflammatory markers and lung epithelial cell death.

\section{Materials and Methods}

\subsection{Materials and Reagents}

The Citrus junos Tanaka peel used in this study was obtained from the Goheung Agricultural Cooperative Federation (Goheung, Korea), and the Citrus junos Tanaka peel extract (specimen voucher number: GFS-\#003) used in this study was verified and stored in the specimen room located in the Department of Food Science of Gyeongsang National University. It was ground using a blender and extracted with 10 volumes of hot distilled water $\left(60{ }^{\circ} \mathrm{C}\right.$ to $\left.100{ }^{\circ} \mathrm{C}\right)$ for $24 \mathrm{~h}$. The extract (hereafter CPE) was filtered through a filter paper (Whatman; Maidstone, UK), freeze-dried, and stored in a $-80^{\circ} \mathrm{C}$ deep-freezer. Naringin $(\geq 95 \%)$ and $\mathrm{PM}_{10}(\mathrm{ERM}-\mathrm{CZ120})$ used for certified reference material were purchased from Sigma (St. Louis, MO, USA).

\subsection{Analysis of Naringin Contents}

The Agilent 1260 series (Agilent Technologies; Santa Clara, CA, USA) that was equipped with a quaternary pump, an online degasser, an auto plate-sampler, and a photodiode array detector with an Agilent ZORBAX Eclipse XDB-C18 column $(4.6 \mathrm{~mm} \times 150 \mathrm{~mm}$, $5 \mu \mathrm{m}$ particle size) was used for the separation. Solvent A consisted of $0.1 \%$ formic acid in water and solvent $\mathrm{B}$ consisted of $0.1 \%$ formic acid in acetonitrile. The solvent gradient was listed: $10 \%$ B at $0-5 \mathrm{~min} ; 10-20 \%$ B at $5-13 \mathrm{~min} ; 20 \% \mathrm{~B}$ at $13-20 \mathrm{~min} ; 20-50 \%$ B at $20-25 \mathrm{~min}$; $50-80 \%$ B at 25-30 min. The composition was next held at $95 \%$ B for $5 \mathrm{~min}$, and then it returned to its initial conditions and was maintained for $5 \mathrm{~min}$ to equilibrate the column. The detection wavelength was $280 \mathrm{~nm}$. The column temperature was maintained at $28{ }^{\circ} \mathrm{C}$ with a thermostatically controlled column compartment. The flow rate was $1.0 \mathrm{~mL} / \mathrm{min}$, and the injection volume was $10 \mu \mathrm{L}$. 


\subsection{Cell Culture}

The human lung carcinoma cell line NCI-H460 was obtained from the Korean cell line bank (Seoul, Korea). Cells were cultured in RPMI-1640 (Thermo-fisher Scientific, Waltham, MA, USA) supplemented with 10\% fetal bovine serum, $1 \%$ penicillin-streptomycin, and $0.2 \% \mathrm{NaHCO}_{3}$, and grown in a $5 \% \mathrm{CO}_{2}$ incubator at $37{ }^{\circ} \mathrm{C}$.

\subsection{Intracellular Anti-Oxidative Assay}

NCI-H460 cells were seeded at a density of $3 \times 10^{4}$ cells per well on a 96-well plate. After $24 \mathrm{~h}$, the growth medium was removed, and the wells were washed with phosphatebuffered saline solution. Then, $100 \mu \mathrm{L}$ of the samples $(800 \mu \mathrm{g} / \mathrm{mL}$, both NAR and CPE) were treated on the cell with $25 \mu \mathrm{M}$ of dichloro-dihydro-fluorescein diacetate. After an hour, the wells were washed with phosphate-buffered saline solution again and $600 \mu \mathrm{M}$ of $2,2^{\prime}-$ azobis(2-methylpropionamidine) dihydrochloride (AAPH) or $0.4 \mathrm{mg} / \mathrm{mL}$ of $\mathrm{PM}_{10}$ was added to the cells in $100 \mu \mathrm{L}$ of Hank's balanced sale solution. The plate was placed into a fluorescence plate-reader and measured with 538/485 nm every $5 \mathrm{~min}$ for an hour. The negative control wells contained cells treated with dichloro-dihydro-fluorescein diacetate and Hank's balanced sale solution without $\mathrm{AAPH}$ or $\mathrm{PM}_{10}$. Assay results were expressed as a percent of control.

\subsection{Cell Viability Assay}

NCI-H460 cells were plated onto a 96-well plate at a density of $3 \times 10^{4}$ cells per well and exposed to naringin or CPE $(800 \mu \mathrm{g} / \mathrm{mL})$ and $\mathrm{PM}_{10}(400 \mu \mathrm{g} / \mathrm{mL})$ for $12 \mathrm{~h}$. Thereafter, the 3-(4,5-dimethylthiazol-2-yl)-2,5-diphenyltetrazolium bromide reagent solution was added to each well at $37{ }^{\circ} \mathrm{C}$. After two hours, the formazan dissolved with dimethyl sulfoxide $(100 \mu \mathrm{L})$, and absorbance was measured at $595 \mathrm{~nm}$ using a microplate reader.

\subsection{Animal and Treatment}

Male 7-week-old BALB/c mice were obtained from the Raonbio (Yongin, Korea). The animals were housed in a controlled environment with $12 \mathrm{~h}$ light and dark cycles. The mice received water and a standard diet ad libitum. All mice were randomly divided into five groups $(n=8)$ as follows: (1) NEG (saline + vehicle), (2) POS (saline $\left.+\mathrm{PM}_{10}\right)$, (3) NAR (naringin $100 \mathrm{mg} / \mathrm{kg}+\mathrm{PM}_{10}$ ), (4) CPL (CPE $100 \mathrm{mg} / \mathrm{kg}+\mathrm{PM}_{10}$ ), (5) CPH (CPE $\left.400 \mathrm{mg} / \mathrm{kg}+\mathrm{PM}_{10}\right)$. Naringin and CPE were treated orally with saline once daily for 7 days, and $100 \mathrm{mg} / \mathrm{kg}$ of $\mathrm{PM}_{10}$ was treated by intranasal administration only once on the last day. After $6 \mathrm{~h}$ of $\mathrm{PM}_{10}$ treatment, all groups were sacrificed using an overdose of avertin. The lung and bronchoalveolar lavage fluid (BALF) was collected for immunoblot analysis, histochemical analysis, and enzyme-linked immunosorbent assays (ELISAs).

\subsection{Histological Analysis}

The isolated lung tissues were fixed in $10 \%$ formalin, dehydrated using a graded series of alcohol, and embedded in paraffin. The paraffin molds were sectioned with $3 \mu \mathrm{m}$. Thereafter, they were deparaffinized, rehydrated with alcohol, and stained with hematoxylin and eosin.

\subsection{Immunoblot Analysis}

Lung tissues were homogenized in lysis buffer with protease inhibitor and phenylmethylsulfonyl fluoride to prepare protein lysates. Proteins were resolved by $10 \%$ sodium dodecyl sulfate-polyacrylamide gel electrophoresis and transferred to nitrocellulose membranes. The membranes were blocked with $3 \%$ bovine serum albumin solution for $1 \mathrm{~h}$ at room temperature. Then, the membranes were probed with primary antibodies overnight and incubated with peroxidase-conjugated secondary antibodies. The protein bands were visualized using enhanced chemiluminescence reagent on an ImageQuant LAS-4000 imager (General Electric, Pittsburgh, PA, USA) and quantified using ImageJ software (National Institute of Health, Bethesda, MD, USA). 


\subsection{ELISA Assay}

BALF was collected and stored at $-80{ }^{\circ} \mathrm{C}$. Tumor necrosis factor- $\alpha$ (TNF- $\left.\alpha\right)$ and interleukin-1 $\beta$ (IL-1 $\beta$ ) levels in BALF were measured using mouse-specific ELISA kits according to manufacturer's instructions (Abcam; Cambridge, UK).

\subsection{Statistical Analysis}

Data were analyzed by $t$-test and one-way analysis of variance using SAS software (SAS Institute, Cary, NC, USA). The least-squares mean option using a Tukey-Kramer adjustment was used for multiple comparisons among the experimental groups. Data are shown as the means \pm SEM (standard error of the mean). $p$-values of $<0.05$ were considered statistically significant.

\section{Results and Discussion}

\subsection{Naringin Content Was Highest in the $60^{\circ} \mathrm{C}$ Water Extract of Citrus junos Tanaka Peel}

The peel of Citrus junos Tanaka, which is rich in active compounds such as phenolic compounds (e.g., limonene, rutin, naringin, narirutin, hesperidin, and neohesperidin), is mainly used as a dried product for herbal medicine, tea, or beverages [7,13-16]. The various functions of these compounds have been reported such as immune and inflammation regulation [14,17-21]. In particular, naringin has been reported in several studies, showing a key protective effect against oxidative stress $[17,22]$. To identify optimal extraction temperature, Citrus junos Tanaka peel was extracted using water as a solvent under conditions of $60^{\circ} \mathrm{C}, 80^{\circ} \mathrm{C}$, and $100^{\circ} \mathrm{C}$; these temperatures were selected to reflect its daily use. After this, the contents of naringin in each fraction were subjected to the high-performance liquid chromatography system (see detailed analytical conditions in the Materials and Methods section) with a commercial reference standard for quantification. We noticed that naringin contents tended to decrease with higher temperature, although it was not greatly impacted. Among the conditions, $\mathrm{CPE}$ prepared at $60^{\circ} \mathrm{C}$ presented the highest naringin content, and thus it was selected for further in vitro and in vivo analyses (7.74 mg/g naringin; Figure 1).

\subsection{CPE Treatment Protected Cells from PM 10 -Induced Oxidative Stress}

$\mathrm{PM}_{10}$ provokes oxidative stress to the keratinocyte, bronchial, and alveolar epithelial cells due to its direct exposure [23,24]. Before checking the protective activity, we executed cytotoxicity tests using the MTT assay to determine the best concentration of naringin and CPE (Supplementary Material Figure S1). The protective potential of CPE was first examined, as a proof of concept, using in vitro intracellular anti-oxidative assay; the AAPH was used as a positive control in the model. Both AAPH and $\mathrm{PM}_{10}$ treatment significantly increased intracellular ROS levels compared to the NEG group $(1000 \%$ and $1450 \%$, respectively; $p<0.05$; Figure 2A), and quercetin, a reference antioxidant, reduced ROS generation successfully ( $90 \%$ compared to POS group; $p<0.05$; Figure 2B), guaranteeing that the experimental model works well. As expected, the groups treated with naringin and $\mathrm{CPE}$ showed a dramatic reduction in ROS generation in the model ( $35 \%$ and $23 \%$, respectively; $p<0.05$; Figure 2B). Oxidative stress can cause apoptotic cell death, which is an initial response to the development of respiratory manifestations $[25,26]$. We confirmed that cell viability was significantly decreased in the $\mathrm{PM}_{10}$-treated group ( $28 \%$ compared to the NEG group; $p<0.05)$, while CPE- and naringin treated groups showed suppressed cell death compared to the $\mathrm{PM}_{10}$-treated group ( $>90 \%$ compared to the NEG group; $p<0.05$ compared to POS group; Figure 2C). With the potent anti-oxidative capacity and protection against $\mathrm{PM}_{10}$-induced cell deaths, the in vitro study results led us to further verify physiological effects in a whole-body animal model system. 


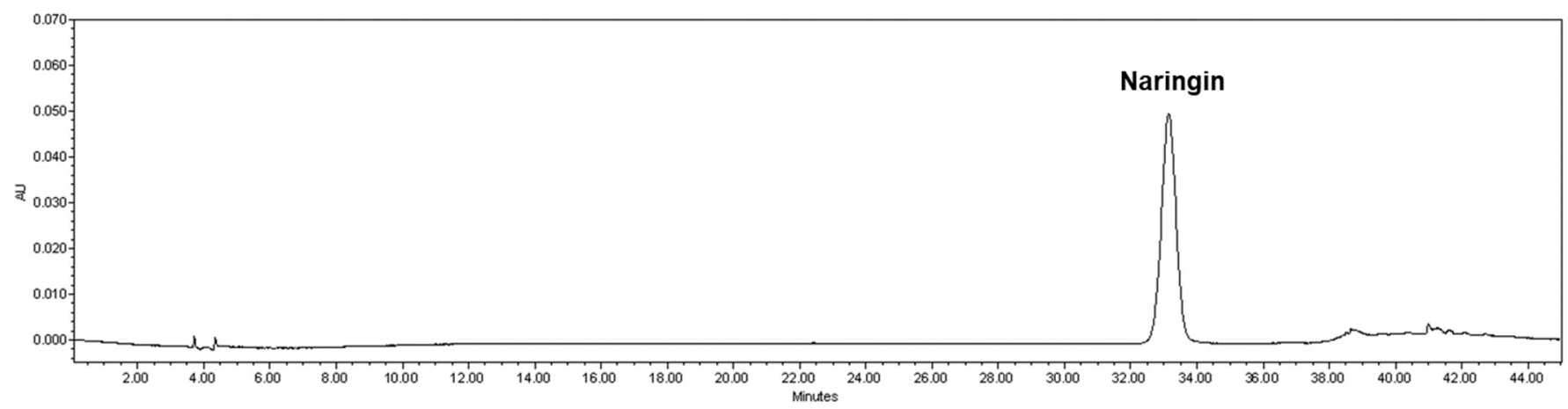

(A)

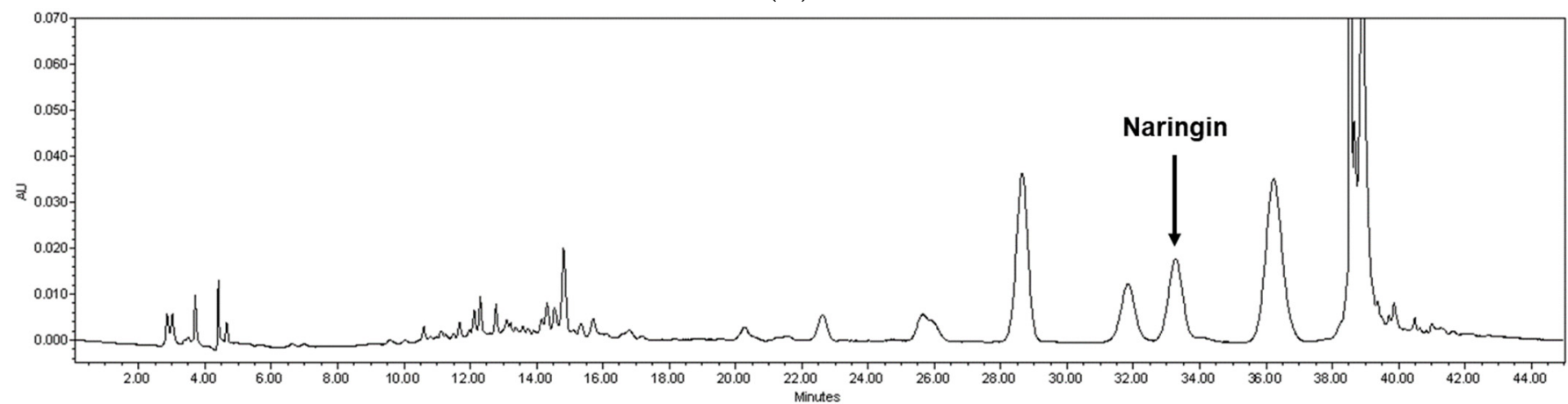

(B)

Figure 1. Quantification of naringin from CPE. Representative high-performance liquid chromatography chromatogram (at $280 \mathrm{~nm}$ ) of the (A) naringin reference standard and (B) CPE prepared at $60{ }^{\circ} \mathrm{C}$. The arrowed peak has been identified as naringin. CPE, Citrus junos Tanaka peel extract.

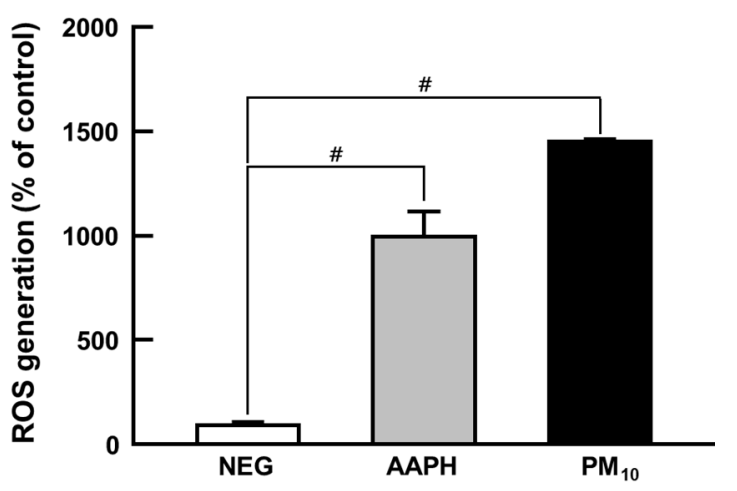

(A)

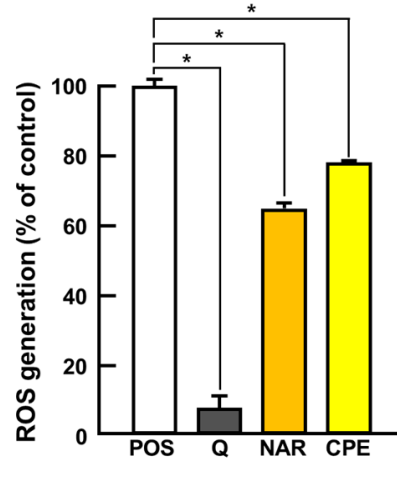

(B)

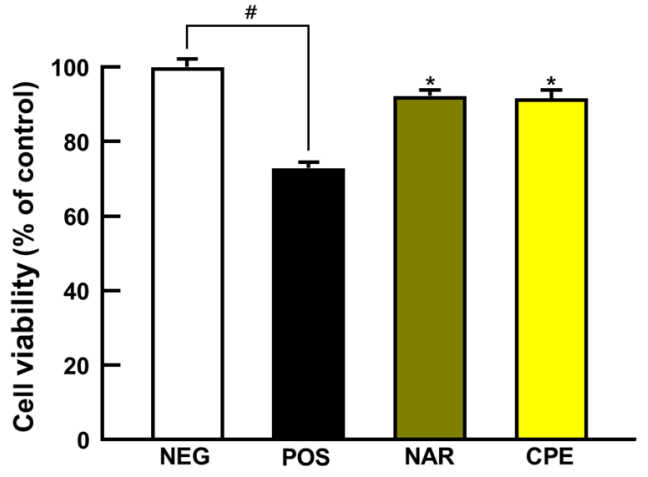

(C)

Figure 2. Protective effects of $\mathrm{CPE}$ and NAR against $\mathrm{PM}_{10}$-induced oxidative stress in NCI-H460 cell line. (A) ROS generation, (B) intracellular antioxidant activity, and (C) cell viability. All values are expressed as mean \pm SEM. $p$-value less than 0.05 was considered statistically significant. \# indicates statistical significance compared to the NEG group, and * indicates statistical significance compared to the POS group. AAPH, 2,2'-azobis(2-methylpropionamidine) dihydrochloride; CPE, Citrus junos Tanaka peel extract; NAR, naringin; $\mathrm{PM}_{10}$, particulate matter 10; $\mathrm{Q}$, quercetin; ROS, reactive oxygen species.

\subsection{CPE Alleviated PM10-Induced Pneumonitis via Suppression of Pro-Inflammatory Cytokines}

To determine whether the administration of $\mathrm{CPE}$ and naringin could alleviate $\mathrm{PM}_{10^{-}}$ induced lung inflammation, mice were subjected to oral administration of $\mathrm{CPE}$ and naringin for 7 days; after this, to induce pneumonitis phenotypes, the mice were subjected to intranasal injection of $\mathrm{PM}_{10}(100 \mathrm{mg} / \mathrm{kg}$ body weight $)$ at the last day and sacrificed after $6 \mathrm{~h}$. The 
naringin and low-dose CPE concentration (i.e., $100 \mathrm{mg} / \mathrm{kg}$ body weight) were determined on the basis of the work of previous papers using similar samples (i.e., naringin and natural product extracts), and the higher dose of CPE was chosen to confirm the dose-dependent response of CPE [11,27-33]. As an initial response against $\mathrm{PM}_{10}$, inflammatory immune cells (e.g., eosinophils and neutrophils) are recruited on the site, followed by air space enlargement and detachment, all of which are typical pneumonitis manifestations [34,35].

To determine if our $\mathrm{PM}_{10}$ treatment conditions induce pneumonitis phenotypes in mice, histological staining was performed. As presented in Figure 3, lung pathology assessment shows that bronchoalveolar structure was destructed by $\mathrm{PM}_{10}$ treatment, while, qualitatively, sample treatment groups showed marginal improvements; specifically, pulmonary alveolar size was increased in the POS group (457\% compared to NEG group; $p=0.0572$; Figure 3B), whereas the NAR, CPL, and CPH presented protection, albeit statistical significance was not reached $(54 \%, 58 \%$, and $49 \%$ compared to POS group, respectively; $p=0.1224, p=0.0915, p=0.1737$, respectively; Figure 3B).

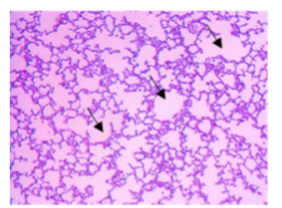

NEG

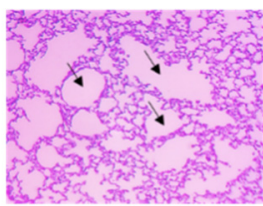

POS

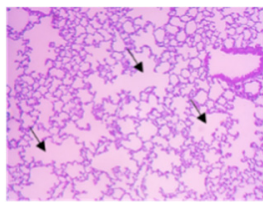

NAR

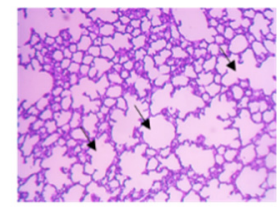

CPL

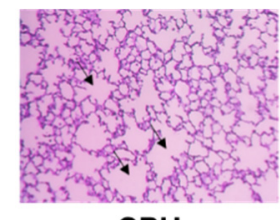

$\mathrm{CPH}$

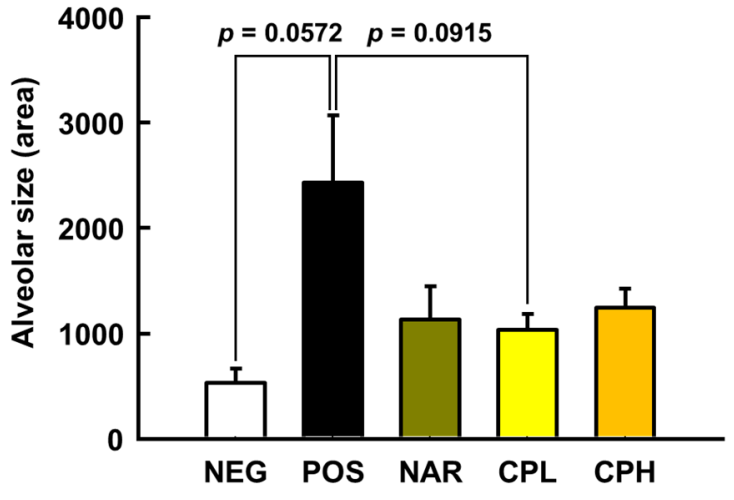

(B)

(A)

Figure 3. Histological analysis of representative hematoxylin and eosin-stained lung sections, and lung pathology assessment of $\mathrm{PM}_{10}$-induced lung damage. (A) Hematoxylin and eosin-stained sections; (B) alveolar size quantification. All values are expressed as mean \pm SEM. CPL, Citrus junos Tanaka peel extract low concentration; $\mathrm{CPH}$, Citrus junos Tanaka peel extract high concentration; NAR, naringin; NEG, negative control; POS, positive control.

To understand preventive mechanisms of CPE at the molecular level, pro-inflammatory cytokines, TNF- $\alpha$ and IL-1 $\beta$, in BALF were first analyzed. In agreement with our histological observations, the pro-inflammatory cytokines were both dramatically increased by $\mathrm{PM}_{10}$ treatment $(750 \%$ for TNF- $\alpha$ and $144 \%$ for IL-1 $\beta$ compared to NEG group, respectively; $p<0.05$; Figure 4), while naringin and a low dose of CPE decreased TNF- $\alpha(65 \%$ and $38 \%$ for naringin and CPL, compared to the POS group, respectively; $p<0.05)$ and IL-1 $\beta$ $(\approx 31 \%$ for both naringin and CPL, compared to the POS group, respectively; $p<0.05$; Figure 4). TNF- $\alpha$ is a pro-inflammatory cytokine and is secreted by immunocytes such as macrophages, monocytes, and neutrophils; it responds to inflammation or external stress factors to transactivate NF- $\mathrm{B}$ and its downstream target genes [25]. Researchers have shown that TNF- $\alpha$ mediates the recruitment of neutrophils and eosinophils during airway inflammation [36]. On the other hand, epithelial cells were damaged, and danger signals (e.g., uric acid and adenosine triphosphate) activated toll-like receptor 4 and inflammasome (e.g., NOD-like receptor porin domain-containing protein 3). NF- $\mathrm{BB}$ is translocated to the nucleus through the activated toll-like receptor 4 signaling pathway, thereby pro-IL- $1 \beta$ is a transcript and is activated as IL- $1 \beta$ by caspase 1 provokes a neutrophilic and eosinophilic inflammatory response [37]. Consequently, the increase of TNF- $\alpha$ and IL-1 $\beta$ in BALF indicated that intranasal treatment of $\mathrm{PM}_{10}$ provokes pneumonitis, while CPE and naringin treatment counteracts against NF- $\mathrm{kB}$-mediated inflammatory responses due to decreased TNF- $\alpha$ and IL-1 $\beta$. However, at this moment, it is unclear as to why a high dose of CPE 
(i.e., CPH in Figure 4) failed to recapitulate the protection. Further pharmacokinetic, as well as bioavailability studies, are warranted.

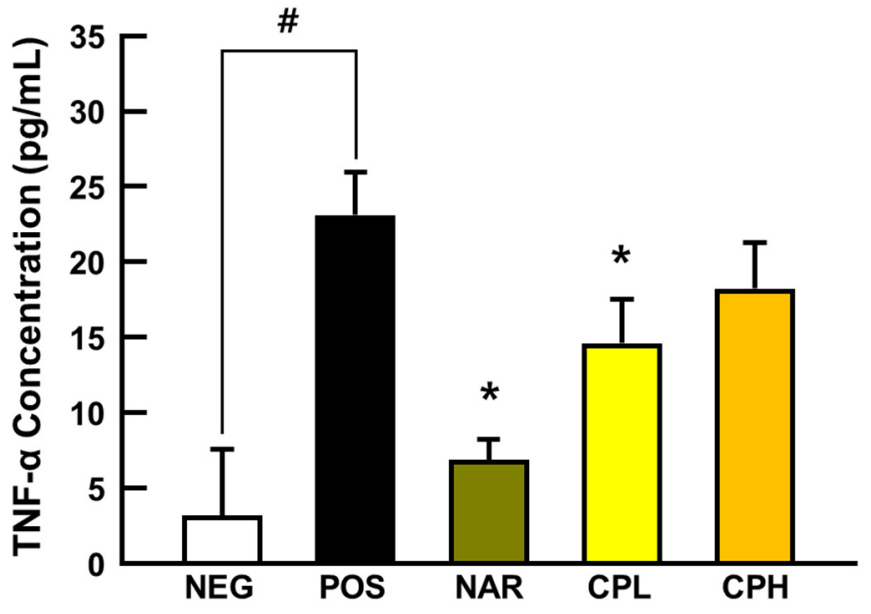

(A)

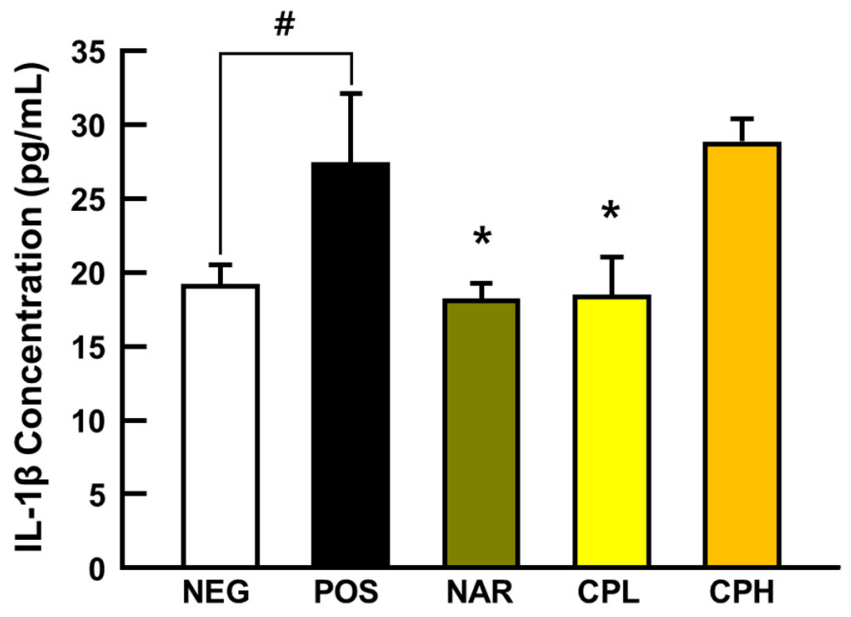

(B)

Figure 4. The expression of pro-inflammatory cytokines in the BALF from $\mathrm{PM}_{10}$-treated mice. (A) TNF- $\alpha$ and (B) IL-1 $\beta$ protein expression. All values are expressed as mean \pm SEM. $p$-value less than 0.05 was considered statistically significant. \# indicates statistical significance compared to the NEG group and * indicates statistical significance compared to the POS group. CPL, Citrus junos Tanaka peel extract low concentration; CPH, Citrus junos Tanaka peel extract high concentration; NAR, naringin; NEG, negative control; POS, positive control.

\subsection{CPE Downregulated NF- $\kappa B$ and Caspase Cascade Signaling Pathways in Lung Tissue}

Overproduction of ROS in the body causes inflammatory responses, which could lead cells to apoptosis, and inhaled $\mathrm{PM}_{10}$ is a well-established inflammation mediator by generating ROS in the lungs [38,39]. To determine whether intranasally administered $\mathrm{PM}_{10}$ induces a local inflammatory response in this model, a representative downstream cytokine of NF- $k$ B, IL-6, was assessed using lung tissues. The expression level of IL6 was significantly increased by $\mathrm{PM}_{10}$ treatment $(158 \%$ compared to NEG group; $p<0.05$; Figure 5A), whereas it was significantly decreased in CPE and naringin administration groups (37\% and 29\% compared to POS group; $p<0.05$; Figure 5A). Relatedly, the mechanism of apoptosis can be divided into two broad categories: intrinsic and extrinsic pathways [40]. When cells recognize DNA damage, mitochondria release cytochrome c, which activates caspase- 9 and caspase- 3 in a cascade, leading to apoptosis in the intrinsic pathway. In the extrinsic pathway, external stimuli such as ROS and/or inflammatory cytokines activate caspase- 8 and subsequently caspase-3, thereby leading to apoptosis [41]. We explored if inhaled $\mathrm{PM}_{10}$, as an external stimulus, triggers the extrinsic apoptosis pathway, secreted Fas, and its downstream apoptotic markers (i.e., c-caspase- 8 and c-caspase-3) that were quantified in the lung tissues.

Fas, c-caspase- 8 , and c-caspase- 3 were significantly increased by $\mathrm{PM}_{10}$ treatment (Fas, 209\%; c-caspase-8, 156\%; c-caspase-3, 202\%, compared to the NEG group; $p<0.05$; Figure 5), while naringin reversed them all (Fas, 60\%; c-caspase- $8,44 \%$; c-caspase-3, 75\%, compared to the POS group; $p<0.05$; Figure 5). Likewise, the CPL had similar protection in c-caspase8 and c-caspase-3 (43\% and 49\%, respectively; $p<0.05$; Figure 5C,D), whereas the CPH only reduced c-caspase-3 (50\% $p<0.05$; Figure 5D). Our observations are in good agreement with others. In a previous study, CPE protected acrolein-induced lung damage by significantly reducing c-caspase-3 and c-parp [11]. Likewise, the caspase cascade and pro-inflammatory reactions are key proteins in the context of airway toxicant-induced pulmonary injury models (e.g., PM) [42-47]. Hence, results herein, in addition to evidence in the literature, collectively indicate that targeting extrinsic apoptosis by mitigating ROS production would 
be an effective approach to mitigate inflammatory responses. Our in vitro data confirm that naringin would be, at least in part, responsible for such production.

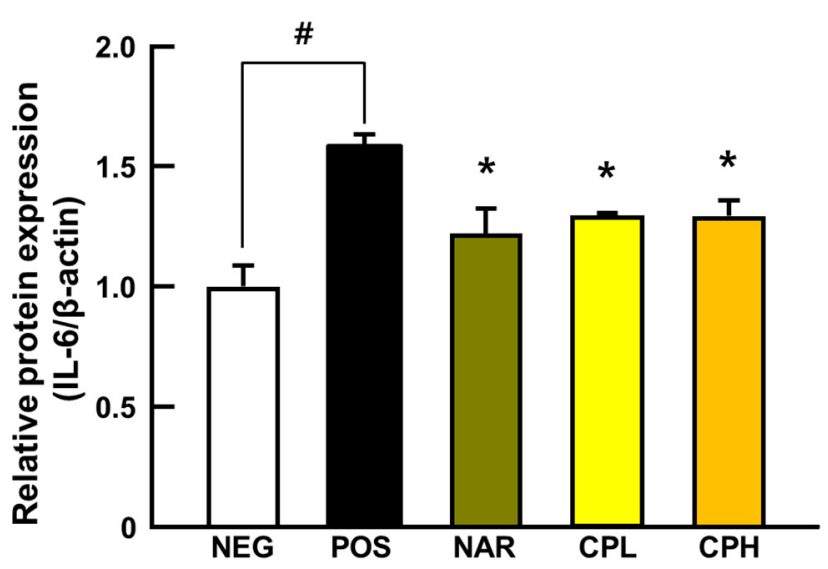

(A)

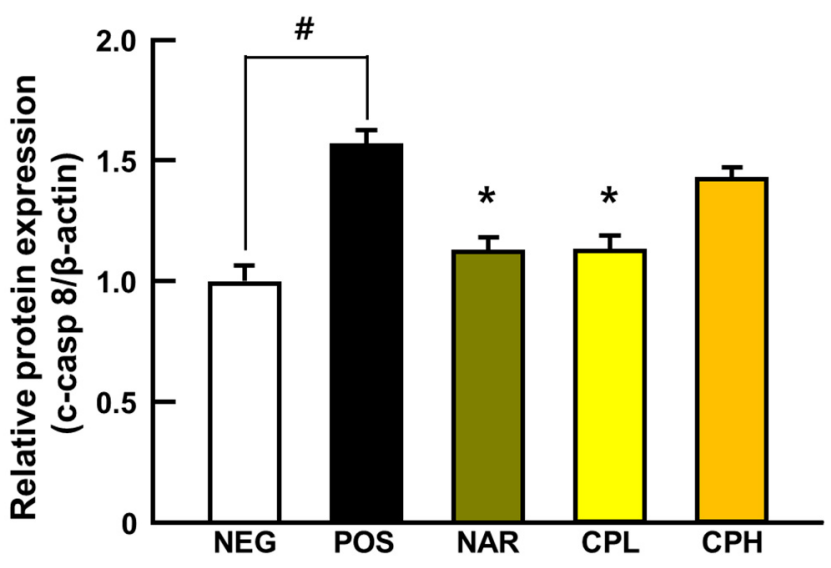

(C)

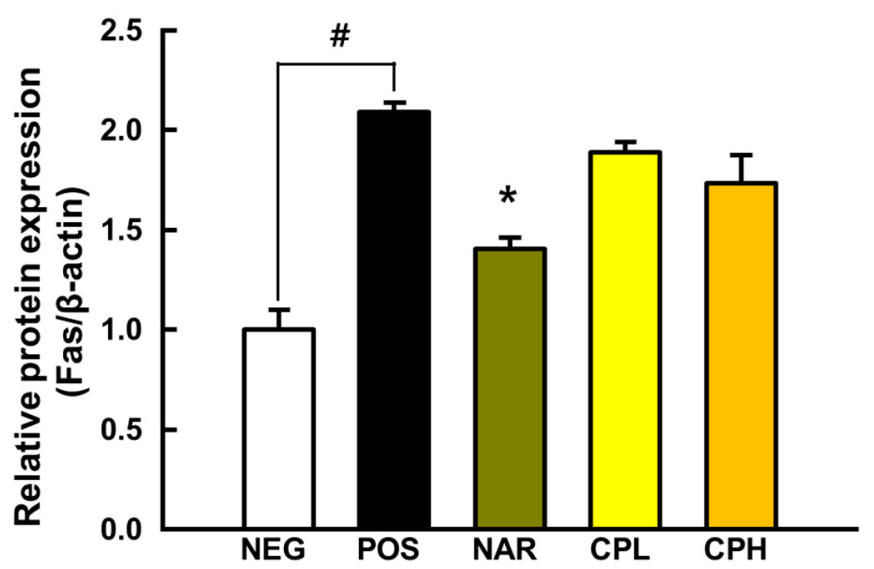

(B)

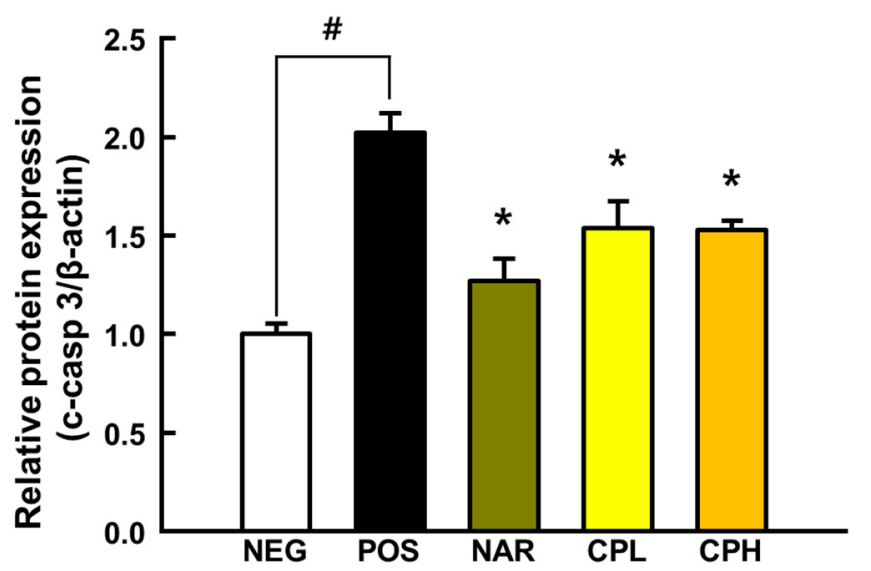

(D)

Figure 5. The expressions of pro-inflammatory cytokine- and apoptosis-related proteins in $\mathrm{PM}_{10^{-}}$ induced lung damage. (A) IL-6, (B) Fas, (C) c-caspase-8, and (D) c-caspase-3 expression. All values are expressed as mean \pm SEM. $p$-value less than 0.05 was considered statistically significant. \# indicates statistical significance compared to the NEG group, and * indicates statistical significance compared to the POS group. CPL, Citrus junos Tanaka peel extract low concentration; $\mathrm{CPH}$, Citrus junos Tanaka peel extract high concentration; NAR, naringin; NEG, negative control; POS, positive control.

A few strengths of the study should be noted. First, we established the contents of naringin in CPE through high-performance liquid chromatography, which allows us to estimate the exact level of exposure of reference constituent from the CPE. Second, we established in vivo pneumonitis via nasal administration, which is more technically challenging yet relevant to reflect inhalation toxicant exposure. To examine dose-dependent responses of $\mathrm{CPE}$, we included both low and high doses of $\mathrm{CPE}$; as a result, we were not able to demonstrate further protection from the high-dose group (i.e., CPH), which is fundamental information for future pharmacokinetic and toxicity studies. In contrast, weak points also existed. We analyzed the content of naringin, which is expected to be a major bioactive of $\mathrm{CPE}$, through high-performance liquid chromatography, but other miscellaneous phenolic compounds were not quantified for this study. Therefore, it is certainly possible that other potential phytonutrients may have played roles that can be further investigated in future studies. Relatedly, we have shown that naringin inhibits ROS generation in vitro, in which its potential was compared with a known radical scavenging 
compound (i.e., quercetin). Thus, the inclusion of a positive control group (using a known ROS scavenger) might have provided additional insight as to relative potential against $\mathrm{PM}_{10}$-induced respiration damage. Although it was a proof-of-concept study, we used human lung carcinoma, which is not relevant to the prevention study of pneumonitis; perhaps primary normal alveolar epithelial cells would have been a better option. However, our aim to use the in vitro model was to simply examine the intracellular anti-oxidative potential of naringin and CPE before the in vivo study in which the cell study results were reproduced. Second, our study conditions were acute, and hence were not harsh enough to induce further advanced pathological markers (e.g., pulmonary fibrosis); thus, long-term exposure studies might be warranted in the future.

\section{Conclusions}

This study provides evidence that ROS production in lung cells increased by $\mathrm{PM}_{10}$ treatment can induce oxidative damage-induced extrinsic apoptosis, which could affect cell viability. We confirmed that $\mathrm{CPE}$ and naringin treatment decreased intracellular ROS production and increased cell viability of lung cells against $\mathrm{PM}_{10}$-induced oxidative stress. Furthermore, we investigated the protective effect of CPE against oxidative stress by a $\mathrm{PM}_{10}$-induced lung injury mouse model and confirmed that it could alleviate the damage through histological complementation and suppressed the expression of pro-inflammatory cytokines and extrinsic apoptosis-related proteins. In conclusion, these results indicate that $\mathrm{CPE}$ exhibits a protective effect against oxidative stress-induced lung damage in both in vitro and in vivo models. On the basis of these results, the following further studies can be carried out: First, since this study was an acute inflammatory response study, a long-term pre-clinical study might be needed. Further, it is warranted to investigate mechanistic validation(s) with regard to NAR and $\mathrm{CPE}$ on $\mathrm{PM}_{10}$-induced inflammatory signaling pathways. Finally, clinical trials should be conducted in polluted areas or on smokers who are exposed to $\mathrm{PM}_{10}$ in order to determine the clinical potency of CPE and naringin.

Supplementary Materials: The following supporting information can be downloaded at https:// www.mdpi.com/article/10.3390/nu14051101/s1, Figure S1: Cytotoxicity of CPE and NAR treatment on NCI-H460 cell line.

Author Contributions: Conceptualization, Y.-J.K.; formal analysis, D.-H.L., J.-K.W. and W.-Y.H.; investigation, J.-K.W., Y.K., S.C., G.-H.L. and J.-W.P.; resources, Y.-J.K.; data curation, D.-H.L., J.-K.W., Y.K. and B.-K.H.; writing-original draft preparation, D.-H.L., J.-K.W. and Y.-J.K.; writing-review and editing, E.-C.S., W.H., J.-H.P. and J.-K.K.; visualization, D.-H.L. and J.-K.W.; supervision, Y.-J.K. All authors have read and agreed to the published version of the manuscript.

Funding: This research received no external funding.

Institutional Review Board Statement: The animal study protocol was approved by the Ethics Committee of the Korea University Institutional Animal Care and Use Committee (KUIACUC-2019-0078).

Informed Consent Statement: Not applicable.

Data Availability Statement: Not applicable.

Acknowledgments: This research was supported by the BK21 FOUR (Fostering Outstanding Universities for Research) funded by the Ministry of Education (MOE, Korea) and the National Research Foundation of Korea (NRF).

Conflicts of Interest: The authors declare no conflict of interest.

\section{References}

1. Zhang, W.; Lei, T.; Lin, Z.-Q.; Zhang, H.-S.; Yang, D.-F.; Xi, Z.-G.; Chen, J.-H.; Wang, W. Pulmonary toxicity study in rats with PM10 and PM2. 5: Differential responses related to scale and composition. Atmos. Environ. 2011, 45, 1034-1041. [CrossRef]

2. Grahame, T.J.; Schlesinger, R.B. Oxidative stress-induced telomeric erosion as a mechanism underlying airborne particulate matter-related cardiovascular disease. Part. Fibre Toxicol. 2012, 9, 21. [CrossRef] 
3. Park, S.; Seok, J.K.; Kwak, J.Y.; Suh, H.-J.; Kim, Y.M.; Boo, Y.C. Anti-inflammatory effects of pomegranate peel extract in THP-1 cells exposed to particulate matter PM10. Evid. Based Complement. Altern. Med. 2016, 2016, 6836080. [CrossRef]

4. $\quad$ Ko, H.M.; Choi, S.-H.; Kim, Y.; An, E.-J.; Lee, S.-H.; Kim, K.; Jung, H.-J.; Jang, H.-J. Effect of Rosa laevigata on PM10-Induced Inflammatory Response of Human Lung Epithelial Cells. Evid. Based Complement. Altern. Med. 2020, 2020, 2893609. [CrossRef] [PubMed]

5. Kim, D.-W.; Jung, D.-H.; Sung, J.; Min, I.S.; Lee, S.-J. Tart Cherry Extract Containing Chlorogenic Acid, Quercetin, and Kaempferol Inhibits the Mitochondrial Apoptotic Cell Death Elicited by Airborne PM10 in Human Epidermal Keratinocytes. Antioxidants 2021, 10, 443. [CrossRef] [PubMed]

6. Lee, Y.-S.; Min, D.; Park, S.-Y.; Lee, J.; Bae, H. Standardized herbal extract PM014 alleviates fine dust-induced lung inflammation in mice. BMC Complement. Med. Ther. 2020, 20, 270. [CrossRef]

7. Kitahara, T.; Takagi, Y.; Matsui, M. Structure and the synthesis of novel constituents of yudzu peel oil and their conversion to related monoterpenes. Agric. Biol. Chem. 1980, 44, 897-901.

8. Hirota, R.; Roger, N.N.; Nakamura, H.; Song, H.S.; Sawamura, M.; Suganuma, N. Anti-inflammatory Effects of limonene from yuzu (Citrus junos Tanaka) essential oil on eosinophils. J. Food Sci. 2010, 75, H87-H92. [CrossRef]

9. Bharti, S.; Rani, N.; Krishnamurthy, B.; Arya, D.S. Preclinical evidence for the pharmacological actions of naringin: A review. Planta Med. 2014, 80, 437-451. [CrossRef]

10. Abe, H.; Ishioka, M.; Fujita, Y.; Umeno, A.; Yasunaga, M.; Sato, A.; Ohnishi, S.; Suzuki, S.; Ishida, N.; Shichiri, M. Yuzu (Citrus junos Tanaka) Peel attenuates dextran sulfate sodium-induced murine experimental colitis. J. Oleo Sci. 2018, 67, ess17184. [CrossRef]

11. Kim, J.W.; Jo, E.H.; Moon, J.E.; Cha, H.; Chang, M.H.; Cho, H.T.; Lee, M.K.; Jung, W.S.; Lee, J.H.; Heo, W. In Vitro and In Vivo Inhibitory Effect of Citrus junos Tanaka Peel Extract against Oxidative Stress-Induced Apoptotic Death of Lung Cells. Antioxidants 2020, 9, 1231. [CrossRef] [PubMed]

12. Kim, J.K.; Park, J.H.; Ku, H.J.; Kim, S.H.; Lim, Y.J.; Park, J.W.; Lee, J.H. Naringin protects acrolein-induced pulmonary injuries through modulating apoptotic signaling and inflammation signaling pathways in mice. J. Nutr. Biochem. 2018, 59, 10-16. [CrossRef] [PubMed]

13. Zang, L.; Shimada, Y.; Kawajiri, J.; Tanaka, T.; Nishimura, N. Effects of Yuzu (Citrus junos Siebold ex Tanaka) peel on the diet-induced obesity in a zebrafish model. J. Funct. Foods 2014, 10, 499-510. [CrossRef]

14. Kim, S.H.; Hur, H.J.; Yang, H.J.; Kim, H.J.; Kim, M.J.; Park, J.H.; Sung, M.J.; Kim, M.S.; Kwon, D.Y.; Hwang, J.-T. Citrus junos tanaka peel extract exerts antidiabetic effects via AMPK and PPAR-both in vitro and in vivo in mice fed a high-fat diet Evid. Based Complement. Altern. Med. 2013, 2013, 921012.

15. Shim, J.-H.; Chae, J.-I.; Cho, S.-S. Identification and extraction optimization of active constituents in Citrus junos Seib ex TANAKA peel and its biological evaluation. Molecules 2019, 24, 680. [CrossRef] [PubMed]

16. Yoo, K.M.; Lee, K.W.; Park, J.B.; Lee, H.J.; Hwang, I.K. Variation in major antioxidants and total antioxidant activity of Yuzu (Citrus junos Sieb ex Tanaka) during maturation and between cultivars. J. Agric. Food Chem. 2004, 52, 5907-5913. [CrossRef]

17. Shin, D.-B.; Lee, D.-W.; Yang, R.; Kim, J.-A. Antioxidative properties and flavonoids contents of matured citrus peel extracts. Food Sci. Biotechnol. 2006, 15, 357-362.

18. Sawamura, M.; Wu, Y.; Fujiwara, C.; Urushibata, M. Inhibitory effect of yuzu essential oil on the formation of Nnitrosodimethylamine in vegetables. J. Agric. Food Chem. 2005, 53, 4281-4287. [CrossRef]

19. Lan-Phi, N.T.; Shimamura, T.; Ukeda, H.; Sawamura, M. Chemical and aroma profiles of yuzu (Citrus junos) peel oils of different cultivars. Food Chem. 2009, 115, 1042-1047. [CrossRef]

20. Jeon, E.J.; Lee, D.H.; Kim, Y.J.; Ahn, J.; Kim, M.J.; Hwang, J.T.; Hur, J.; Kim, M.; Jang, Y.J.; Ha, T.Y. Effects of yuja peel extract and its flavanones on osteopenia in ovariectomized rats and osteoblast differentiation. Mol. Nutr. Food Res. 2016, 60, 2587-2601. [CrossRef]

21. Yang, H.J.; Hwang, J.T.; Kwon, D.Y.; Kim, M.J.; Kang, S.; Moon, N.R.; Park, S. Yuzu extract prevents cognitive decline and impaired glucose homeostasis in $\beta$-amyloid-infused rats. J. Nutr. 2013, 143, 1093-1099. [CrossRef] [PubMed]

22. Chen, R.; Qi, Q.-L.; Wang, M.-T.; Li, Q.-Y. Therapeutic potential of naringin: An overview. Pharm. Biol. 2016, 54, 3203-3210. [CrossRef] [PubMed]

23. Dias, M.K.H.M.; Madusanka, D.M.D.; Han, E.J.; Kim, M.J.; Jeon, Y.-J.; Kim, H.-S.; Fernando, I.P.S.; Ahn, G. (-)-Loliolide isolated from sargassum horneri protects against fine dust-induced oxidative stress in human keratinocytes. Antioxidants 2020, 9, 474. [CrossRef] [PubMed]

24. Choi, J.H.; Kim, J.S.; Kim, Y.C.; Kim, Y.S.; Chung, N.H.; Cho, M.H. Comparative study of PM2. 5-and PM10-induced oxidative stress in rat lung epithelial cells. J. Vet. Sci. 2004, 5, 11-18. [CrossRef]

25. Kannan, K.; Jain, S.K. Oxidative stress and apoptosis. Pathophysiology 2000, 7, 153-163. [CrossRef]

26. Aoshiba, K.; Nagai, A. Oxidative stress, cell death, and other damage to alveolar epithelial cells induced by cigarette smoke. Tob. Induc. Dis. 2003, 1, 219. [CrossRef]

27. Chen, Y.; Nie, Y.-C.; Luo, Y.-L.; Lin, F.; Zheng, Y.-F.; Cheng, G.-H.; Wu, H.; Zhang, K.-J.; Su, W.-W.; Shen, J.-G. Protective effects of naringin against paraquat-induced acute lung injury and pulmonary fibrosis in mice. Food Chem. Toxicol. 2013, 58, 133-140. [CrossRef]

28. Wu, Y.; Cai, C.; Xiang, Y.; Zhao, H.; Lv, L.; Zeng, C. Naringin Ameliorates Monocrotaline-Induced Pulmonary Arterial Hypertension Through Endothelial-To-Mesenchymal Transition Inhibition. Front. Pharmacol. 2021, 12, 696135. [CrossRef] 
29. Shi, R.; Su, W.-W.; Zhu, Z.-T.; Guan, M.-Y.; Cheng, K.-L.; Fan, W.-Y.; Wei, G.-Y.; Li, P.-B.; Yang, Z.-Y.; Yao, H.-L. Regulation effects of naringin on diesel particulate matter-induced abnormal airway surface liquid secretion. Phytomedicine 2019, 63, 153004. [CrossRef]

30. Lee, E.; Yun, N.; Jang, Y.P.; Kim, J. Lilium lancifolium Thunb. extract attenuates pulmonary inflammation and air space enlargement in a cigarette smoke-exposed mouse model. J. Ethnopharmacol. 2013, 149, 148-156. [CrossRef]

31. Kwak, H.G.; Lim, H.-B. Ligustrum lucidum fruits extract inhibits acute pulmonary inflammation in mice. Korean J. Med. Crop Sci. 2013, 21, 323-328. [CrossRef]

32. Kwak, H.-G.; Lim, H.-B. Inhibitory effects of Cnidium monnieri fruit extract on pulmonary inflammation in mice induced by cigarette smoke condensate and lipopolysaccharide. Chin. J. Nat. Med. 2014, 12, 641-647. [CrossRef]

33. Pinheiro, A.J.M.C.R.; Gonçalves, J.S.; Dourado, Á.W.A.; de Sousa, E.M.; Brito, N.M.; Silva, L.K.; Batista, M.C.A.; de Sá, J.C.; Monteiro, C.R.A.V.; Fernandes, E.S. Punica granatum L. leaf extract attenuates lung inflammation in mice with acute lung injury. J. Immunol. Res. 2018, 2018, 6879183. [PubMed]

34. Milano, M.; Dongiovanni, P.; Artoni, A.; Gatti, S.; Rosso, L.; Colombo, F.; Bollati, V.; Maggioni, M.; Mannucci, P.; Bertazzi, P. Particulate matter phagocytosis induces tissue factor in differentiating macrophages. J. Appl. Toxicol. 2016, 36, 151-160. [CrossRef] [PubMed]

35. Zagariya, A.; Bhat, R.; Uhal, B.; Navale, S.; Freidine, M.; Vidyasagar, D. Cell death and lung cell histology in meconium aspirated newborn rabbit lung. Eur. J. Pediatr. 2000, 159, 819-826. [CrossRef]

36. Lukacs, N.W.; Strieter, R.M.; Chensue, S.W.; Widmer, M.; Kunkel, S.L. TNF-alpha mediates recruitment of neutrophils and eosinophils during airway inflammation. J. Immunol. 1995, 154, 5411-5417. [PubMed]

37. Besnard, A.-G.; Togbe, D.; Couillin, I.; Tan, Z.; Zheng, S.G.; Erard, F.; Le Bert, M.; Quesniaux, V.; Ryffel, B. Inflammasome-IL-1Th17 response in allergic lung inflammation. J. Mol. Cell Biol. 2012, 4, 3-10. [CrossRef]

38. Simon, H.-U.; Haj-Yehia, A.; Levi-Schaffer, F. Role of reactive oxygen species (ROS) in apoptosis induction. Apoptosis 2000, 5, 415-418. [CrossRef]

39. Yun, Y.; Gao, R.; Yue, H.; Li, G.; Zhu, N.; Sang, N. Synergistic effects of particulate matter (PM10) and SO $\mathrm{SO}_{2}$ on human non-small cell lung cancer A549 via ROS-mediated NF-кB activation. J. Environ. Sci. 2015, 31, 146-153. [CrossRef]

40. Putcha, G.V.; Harris, C.A.; Moulder, K.L.; Easton, R.M.; Thompson, C.B.; Johnson, E.M., Jr. Intrinsic and extrinsic pathway signaling during neuronal apoptosis: Lessons from the analysis of mutant mice. J. Cell Biol. 2002, 157, 441-453. [CrossRef]

41. Hongmei, Z. Tianjin, China. Extrinsic and Intrinsic Apoptosis Signal Pathway Review; InTechOpen: London, UK, 2012.

42. Deng, X.; Zhang, F.; Wang, L.; Rui, W.; Long, F.; Zhao, Y.; Chen, D.; Ding, W. Airborne fine particulate matter induces multiple cell death pathways in human lung epithelial cells. Apoptosis 2014, 19, 1099-1112. [CrossRef] [PubMed]

43. Farina, F.; Sancini, G.; Mantecca, P.; Gallinotti, D.; Camatini, M.; Palestini, P. The acute toxic effects of particulate matter in mouse lung are related to size and season of collection. Toxicol. Lett. 2011, 202, 209-217. [CrossRef] [PubMed]

44. Farina, F.; Sancini, G.; Battaglia, C.; Tinaglia, V.; Mantecca, P.; Camatini, M.; Palestini, P. Milano summer particulate matter (PM10) triggers lung inflammation and extra pulmonary adverse events in mice. PLoS ONE 2013, 8, e56636. [CrossRef] [PubMed]

45. Chan, Y.L.; Wang, B.; Chen, H.; Ho, K.F.; Cao, J.; Hai, G.; Jalaludin, B.; Herbert, C.; Thomas, P.S.; Saad, S. Pulmonary inflammation induced by low-dose particulate matter exposure in mice. Am. J. Physiol. Lung Cell. Mol. Physiol. 2019, 317, L424-L430. [CrossRef]

46. Happo, M.; Salonen, R.; Hälinen, A.; Jalava, P.; Pennanen, A.; Dormans, J.; Gerlofs-Nijland, M.; Cassee, F.; Kosma, V.-M.; Sillanpää, M. Inflammation and tissue damage in mouse lung by single and repeated dosing of urban air coarse and fine particles collected from six European cities. Inhal. Toxicol. 2010, 22, 402-416. [CrossRef] [PubMed]

47. Dagher, Z.; Garçon, G.; Billet, S.; Gosset, P.; Ledoux, F.; Courcot, D.; Aboukais, A.; Shirali, P. Activation of different pathways of apoptosis by air pollution particulate matter (PM2.5) in human epithelial lung cells (L132) in culture. Toxicology 2006, 225, 12-24. [CrossRef] [PubMed] 